\title{
THE PROTECTIVE EFFECT OF ASCORBIC ACID ON THE HISTOLOGICAL CHANGES CAUSED BY THE HERBICIDE (RONSTAR) IN NILOTIC CATFISH : CLARIAS LAZERA (C. GARIEPINUS)
}

\author{
Elsayed A.Khallaf ${ }^{1}$; Sobhy E. Hassab Elnabi ${ }^{1}$; Zaki T. Zaki ${ }^{3}$ \\ and Osama M. Badr
}

(1)Dept. of Zoology,Faculty of Science,Minufiya University,Egypt, (3) Dept. of Zoology; Faculty of Science,Al-Azhar University, Egypt ; (4) Institute of Genetic Engineering and Biotechnology, Sadat City,Minufiya University,Egypt.

Key words: Herbicide Ronstar; Claria lazera; histologicl changes; liver; kidney; Ascorbic acid.

\section{ABSTRACT}

R onstar was applied at concentrations of $2.0,5.75$ and $9.5 \mathrm{mg} / \mathrm{L}$. RHistological alterations were determined in liver and kidney of the catfish Clarias lazera.

The histological changes in liver of catfish $C$. lazera intoxicated with different doses of Ronstar, included dilation of the blood veins and sinusoids, vacuolation in the cytoplasm and pyknosis in the nuclei of the hepatocytes, haemorrhage is also noticed in the veins and sinusoids.

The phagocytic Kupffer and endothelial cells are also abundant as an immunoresponse reaction. The vacuolation is the most frequent histological alteration observed at all tested doses of Ronstar.

Ascorbic acid (10mg/lkg of body weight)was reported to reduce some of the histological damage occurred in the liver tissue. It alleviated the rate of pyknosis and vacuolation. The rate of ascorbic acid healing effect depends on the Ronstar tested dose.

Ronstar induced different histological alterations in the kidney of the catfish $C$. lazera The glomeruli became expanded and their capillaries were extended, the subcapsular space enlarged or disappeared. The haemopoietic tissue exhibited some vaculation and the renal tubules were swollen or degenerated. Some of them took an irregular shape. The expanded glomeruli with extended capillaries 
Elsayed A.Khallaf $e t$ al.

were the most frequent histological alteration observed in the different doses of Ronstar.

Ascorbic acid induced some amelioration in the histological structure of kidney at all tested doses of Ronstar. It decreased the rate of glomerular expansion or caused a restoration to its normal shape, rate of the extending of the glomerular capillaries was also decreased. The subcapsular space restored its normal appearance.

The rate of vacuolation was alleviated in the haemopoietic tissue, while some of the renal tubules tend to be normal.

At higher doses of the Ronstar, the healing effect of ascorbic acid became less potent.

\section{INTRODUCTION}

The catfish $C$. lazera, is an important nilotic catfish which is known of its tolerability to various environmental factors because of its ability to breath atmospheric air directly.

Herbicides (including Ronstar) are a group of pesticides, widely used in agriculture to control wild grasses and weeds in many crops such as rice, barley, wheat and soyabean. They reach water resources, through out run-off from cultivated lands, causing toxic effects to aquatic animals including fish.

Ascorbic acid(Vitamin C) is a strong reducing agent and there is evidence to show that it has antitoxic properties (Mirvish,1975 and Eichbaum et al.,1977). Yamamoto et al. (1981) indicated that copper toxicity could be decreased by dietary addition of L-ascorbic acid in rainbow trout. In catfish, Mehrle and Mayer (1976) found that a diet containing high concentration of L-ascorbic acid increased their tolerance to the chronic effects of toxaphene.According to Matkovics et al.(1980), ascorbic acid has a positive detoxicating effect against paraquat toxicity. In another study, Matkovics et al.(1982) reported that ascorbic acid reduced and protect mice from the toxicological effects of the herbicide paraquat.

In the present work, the curative effect of ascorbic acid against the toxicity of Ronstar in the freshwater fish Clarias lazera is investigated. 


\section{MATERIAL AND METHODS}

Ronstar (oxadiazon), which is supplied from Kafr El-Zayat Factory for pesticides industry in a concentration (25\%), is widely used in agriculture for control of grasses and broadleaf. Ronstar (oxadiazon) is a nitro-organic herbicide with a molecular formula: $\mathrm{C}_{15} \mathrm{H}_{18} \mathrm{O}_{3} \mathrm{~N}_{2} \mathrm{CL}_{2}$ and it may' be diluted using distilled water.

Ascorbic acid which is supplied from Sigma Chemical Co.(P.O. Box 14508 St. Louis, Mo. 63178 U. S. A) is a colorless, crystalline, water soluble compound, having a molecular formula: $\mathrm{C}_{6}$ $\mathrm{H}_{8} \mathrm{O}_{6}$ and a molecular weight equals to $176.139 / \mathrm{mol}$.

For histological and histopathological studies, two experiments were carried out. The first one is correlated with studying the effect of different dose levels of Ronstar on the histological structure of the liver and kidney of catfish, while the other one is performed to study the effect of ascorbic acid as a curative agent on different histopathological effects induced with Ronstar intoxication.

\section{Experiment ( 1):}

Fish specimens 100 to $150 \mathrm{~g}$ in weight, caught alive by a fisherman, were brought to the laboratory and put into four 50-litre glass aquaria and acclimatized for two days at room temperature, one aquarium included control fish while the remaining three aquaria for the treated fish.

After the period of acclimatization, Ronstar was added to the Nile water of each aquarium at concentrations $2,5.75,9.5 \mathrm{mg} / \mathrm{L}$ respectively. Four fish were used as a control group and batches of 2 fish from each one of the three remaining aquaria were killed at intervals $24,48,72$ and $96 \mathrm{hrs}$ post-treatment. The required organs ( liver \& kidney) were immediately removed from each fish and parts of them from both the control and treated fish were fixed in Bouin's fixative for 24 hours then tissues were washed in tap-water, dehydrated through a graded series of ethyl alcohol, cleared in xylene, embedded in paraffin wax, sectioned at a thickness of 5-7 microns, mounted on glass slides and stained with haematoxylin and eosin ( $\mathrm{H} \& \mathrm{E}$ ) for general morphological studies according to Humason (1979). 
Experiment (2):

In this experiment, intraperitoneal injection of $(10 \mathrm{mg} / \mathrm{l}$ $\mathrm{kg}$. fish) ascorbic acid was carried out on the fish, and at the same time Ronstar with the same previous concentrations $(2,5.75,9.5$ $\mathrm{mg} / \mathrm{L}$ ) added to the aquaria containing the Nile water. The same steps mentioned in the previous experiment were performed.

Careful examination of the stained sections was made to identify the pathological alterations in liver and kidney of the fish, and the possible curative effects of ascorbic acid against the toxicity of Ronstar.

\section{RESULTS}

\section{1)The liver :}

Histological investigations of the liver of $C$. lazera in control slides, revealed that it is not divided into lobules and is composed of branching laminae of hepatocytes separated by sinusoids. The laminae are arranged around central vein (B. V.) into which blood flows from the sinusoids which separate the laminae. The hepatocytes are polygonal cells with spherical nuclei which have slightly, deeply stained nucleolus. The blood sinusoids of the liver are numerous and contain mainly two types of cells, the first type is cells containing thin, small, rod-like nucleus known as endothelial cells, while the second type contain oval dense nuclei, and named macrophages or Kupffer cells (Plate A-1).

At low dose of Ronstar, different histopathological effects were recorded at the different intervals as follows; dilation of the blood vessel and sinusoids, hemorrhage, hepatocyte vacuolation and pyknosis. Ascorbic acid used at this dose, minimized the different changes induced by the herbicide at all time intervals. Thus, the blood vessel restores its normal size and little cytoplasmic vacuolation was still found. Complete recovery due to application of ascorbic acid was noticed at $48 \mathrm{hrs}$ interval, while no evident was reported at $96 \mathrm{hrs}$ interval (Plate A 2\&5).

At the intermediate dose of Ronstar, cytoplasmic vacuolation was predominant at the first two intervals ( 24 \& $48 \mathrm{hrs}$ ), while dilation of the blood vessel, sinusoids and pyknosis of the hepatocytic nuclei were observed at other intervals. The limit of vacuolation was decreased to a great extent at the first two intervals as a result of the bealing effect of ascorbic acid. The blood sinusoids and vessels 
THE PROTECTIVE EFFECT OF ASCORBIC ACID ON THE 209 HISTOLOGICAL CHANGES CAUSED BY' THE HERBICIDE (RONSTAR)

IN NILOTIC CATFISH : CLARIAS LAZERA (C. G.ARIEPINUS)

restored their normal size, pythosis of the hepatocytic nuclei was prevented at the 72 hrs interval as a result of the curative effect of ascorbic acid but failed to induce any sign of alleviation at the $96 \mathrm{hrs}$ interal (Plate A 386).

At the higher cose of Ronstar, severe alterations in the histological structure of the liver and vacuolation were observed. Also, the dilation of the blood vessel and sinusoids were exhibited at a high rate. There is an enlargement of the phagocytic Kupffer cells as a result of ronstar intoxication. Ascorbic acid healing effect was noticed at the first two intervals in minimizing the vacuolation and decreasing the number of Kupffer cells, but did not show complete restoration of blood vessels and sinusoids (Plate A 4\&7).

\section{2) The kidney :}

Histologically, the kidney of $C$. lazera is divided into two parts. The first is the head kidney composed of haemopoietic tissue, lymphoid tissue and pigmented cells. The second part is the trunk kidney,forming the actual renal structure consisted of renal corpuscles and renal tubules. The renal corpuscle is composed of a basement membrane surrounded by squamous cells with flattened nuclei and central spherical glomerulus. On the other hand, the renal tubules consisted of ciliated columnar cells near the renal corpuscles and simple columnar cells, far from the renal corpuscles. The collecting tubules are formed of elongated columnar cells. Also, the kidney showed numerous blood supply (Plate B-1).

At low dose of Ronstar, different histopathological changes were produced in the kidney of $C$. lazera. The glomeruli were expanded, with a thick capsule and their glomerular capillaries were distended. The subcapsular space was enlarged. These effects were less apparent at $48 \mathrm{hrs}$ interval than those at $24 \mathrm{hrs}$. These alterations were developed at the other last intervals.Ascorbic acid exhibited some ameliorations in the histological structure of the kidney at this interval; the rate of glomerular expansion became lesser than those treated with ronstar only, the subcapsular space restored its normal width but the glomerular capillaries were still extending. This picture was not the same at $72 \mathrm{hrs}$ interval because some tubules were still degenerated. On the other hand, there was no sign of amelioration at 96 hrs interval (Plate B 2\&5). 
At the intermediate dose of Ronstar. the subcapsular space was nearly closed. shrinked renal tubules with a narrow lumen were observed beside degenerated ones. At $48 \mathrm{hrs}$ interval,the alterations were the same but the subcapsular space which disappeared at $24 \mathrm{hrs}$. was moderately enlarged at this interval. The histological alterations reached their maxium at the last two intervals (72\&96 hrs); beside the noticed alterations ,new others were induced at these intervals; the renal tubules were vacuolated and very swollen. Ascorbic acid healing effect was partially exhibited at 24 hrs but complete healing effect was exhibited at $48 \mathrm{hrs}$ interval. At $72 \mathrm{hrs}$ interval, signs of healing were apparent in the glomeruli, with no expansion and the renal tubules appeared, with no sign of vacuolation or swelling. AA induced a partial healing effect at $96 \mathrm{hrs}$. This effect was exhibited only in the glomeruli and their capillaries but the renal tubules were still degenerated or having an irregular shape ( Plate B 3\&6).

At the high dose of Ronstar, the histopathological changes accompanied with the treatment of this dose was severe as compared to the same changes produced from the previous doses of Ronstar.AA induced some healing effects at $24 \& 48 \mathrm{hrs}$ by the appearance of the glomeruli and their capillaries but signs of healing effect in the renal tubules were very rare. At $72 \& 96 \mathrm{hrs}$, there was no sign of the histological ameliorations at all; Plate (B) $4 \& 7$.

\section{DISCUSSION}

Exposure of the fish to herbicides in the aquatic environment may not cause immediate death but certainly would induce different abnormalities in the internal organs of the fish. This makes the fish appering normal externally, but injured internally and therefore, it becomes harmful for the human consumer.

The attempts to protect animals and human beings against the deletrious effects of the herbicides are still rare and inconclusive. So, any information gathered in this direction will be valuable and beneficial from toxicological as well as medical points of view.

Histopathological investigation of the liver of $C$. lazera indicated that the Ronstar induced more or less different lesions. However, various toxicosis symptoms occurred.This is examplified in dilatation of the blood veins and sinusoids, vacuolated hepatocyies and pyknosis.Progressive changes are noticed in accordance with the time of exposure. 
Mazhar et al.(1986) demonstrated that the herbicide gallant and mercury, induced liver damage in the freshwater fish $C$. lazera. which was evident by dilatation of blood vessels. Hepatocellular degeneration was also progressed to vacuolar necrosis and this was accompanied by anastomosis of hepatic circulation and increase in Kupffer cells. In accordance, Abo Nour et al.(1992) mentioned that terbutryn herbicide caused intensive hepatic degeneration in C. lazera .

Atrazine induced different histopathological changes in the liver fish. These changes are, vacuolation of hepatocytes and different fatty changes (Weter,1988).

In the present investigation, the toxicosis symptoms of Ronstar are manifested in proliferation of Kupffer and endothelial cells. The proliferation of these cells may be due to the defense mechanism of this fish as a response to the foreign materials. Such findings are in an agreement with Dutta et al.(1994) who concluded that sublethal dose of malathion insecticide triggers the immune system of the catfish; Heteropneustes fossilis. Lesions in the liver, in this study are found to be time and dose dependant.Such finding was similarly reported for toad liver treated with the insecticide lannate (Sakr and Al-Sahhaf,1996).The present finding suggested that, the increase of Kupffer cells can be used as an evidence of early liver toxicity; this suggestion is in a good agreement with the findings of Kadry, (1989). The rate of hepatocytic vacuolation ; dilatation of blood veins and sinusoids become in its high extent at the end of the Ronstar exposure in $C$. lazera. These findings were similarly reported for the same fish liver treated with the herbicide glycophate (Rady,1997); which may be attributed to accumulation of the pesticide. While, earlier, Ibrahim et al.(1991) also reported that mixture of the herbicide gallant and mercury caused destructive effect on the lysosomal membranes of the hepatocytes of $C$. lazera, followed by a release of proteases and other protein splitting enzymes which destroyed some important internal cellular proteins.

In this investigation, Ronstar induced different alterations as detected in the expansion of some glomeruli and their capillaries; enlargement of the subcapsular space and degeneration of the renal tubules.

Abdel-Magid, (1994) proved that the paraquat herbicide caused pathogenesis in kidney tissue that could possibly lead to renal 
dysfunction. Bishayee and Chatterjee, (1994) reponed that the kidney is the most affected organ in the insecticide treated Clarias balrachus In this work. great number of renal tubules appeared with closed luminae and acutely necrotic cells. These findings coincide with those of Curran, (1985) and Burkitt ef ol.(1990) who concluded that, in intoxication, tubular epithelial cells may exhibit marked cytoplasmic degenerative changes and tubular necrosis. Rady, (1997) stated that the herbicide glyphosate induced expansion of the glomeruli and degeneration of the tubul s in the kidney of $C$. lazera; These results coincide nearly with the results of Ronstar intoxication in the same fish.

According to Eichbaum et al. (1977), AA has the ability to induce chemical inactivation of the toxicants in the fish body. While its character as a strong reducing agent, having antitoxic properties; was explained by Darina et al.(1991) who attributed the oxidoreductive active properties of ascorbic acid to the potent scavenger of the free radicals. In the study, after simultaneous treatment of AA, good signs of amelioration are perceptive in the histological structures of both liver and kidney of the catfish; $C$. lazera, treated with different doses of Ronstar. The observed histopathological improvement recorded in this study may be explained either by the ability of AA, as an antioxidant, to modify and minimize the toxicity of ronstar or its active metabolites (detoxification) and/or by stimulating the protein synthetic machinery and therefore, enhancing various enzymatic processes.

From the results of the present study and other mentioned studies, it can be suggested that AA induced partial amelioration in the histological structure of liver and kidney of fishes intoxicated with the herbicide ronstar.

\section{REFERENCES}

Abdel - Magid, S.A.( 1994 ). Structural changes in the kidney of albino rat in response to the administration of paraquat herbicide. J. Egypt.Ger.Soc.Zool.,15( C ): 153-175.

Abo Nour: A.M.; Abo Nour,S. M.and Roushdy, H. M. (1992). Liver dysfunction in the Nile catfish Clarias lazera, affected by the environmental radiation and/or terbutryn herbicide. Egypt. J. Histol.,15(2) : 499-518. 
THE PROTECTIVE EFFECT OF ASCORBIC ACID ON THE 213 HISTOLOGICAL CHANGES CAUSED BY THE HERBICIDE (RONSTAR) IN NILOTIC CATFISH : CLARLAS LAZERA (C GARIEPINUS)

Bishayee,A. and Chatterjee,M. (1994). Increased lipid peroxidation in tissues of the catfish Clarias batrachus, following vanadium treatment : In vivo and in vitro evaluation. J. Inorg. Biochem.,54 (4) : 277-284.

Burkitt, G.;Stevenes, A.and Lowe, J.(1990). "Basic histopathology, A color atlas and text". $2^{\text {nd }}$ ed. Churchill, Livingstone Edinburgh.

Curran, R.C. (1985). "Color atlas of Histopathology". 3rd ed. ; Harvey Miller, London.

Darina, C.;Emil, G. ;Anna, K. and Zdenek, Z. (1991). Effect of vitamins $C \& E$ on toxicity and mutagenicity of hexavalent chromium in rat and guinea pig. Mutat. Res., 262 : 41-46.

Dutta, M. H.; Munshi, D. J. and Roy, K. P. (1994). Malathion induced changes in the lymphatic system of a catfish, Heteropneustes fossilis. Integ. Compa. Biol.,34 (5): 50-53.

Eichbaum, F.W.; Guedes, A. O. ; Palermo Neto, J. and Carvalho,F. V. (1977). Protecting effect of ascorbic acid in strychnine poisoning and in tetanus (experiments in fish,mice and rats). Int. J. Vitm. Nutr. Res. Beih.,16: 31-39.

Humason, G. L.(1979). "Animal Tissue Techniques" 2nd ed. Freeman, W. H. and Company, pp.661.

Ibrahim, M. S.; Abd-Allah, G. A. ; Abdel-Baky, T. E. and Bahnsawy, M. H. (1991). Toxic effects of environmental pollution by herbicide gallant and mercury on liver function of the Nile catfish Clarias lazera. J.Egypt.Ger.Soc.Zool.,6(A):189-199.

Kadry, S. M. (1989). Studies on the effect of cypermethrin on the tissues of the freshwater catfish Clarias lazera, 1-liver. Egypt. J. Histol.,12 (2) : 271-276. 
Matkovics, B.; K. Barabas; L. Szabo and G. Berencsi (1980). In vivo study of the mechanism of protective effects of ascorbic acid and reduced glutathione in paraquat poisoning. Gen. Pharmac.,11: 455-461.

Matkovics, B. ; K. Barabas; SZ. I. Varga; L. Szabo and G. Berencsi (1982). Some new data to the ioxicological effects of paraquat and the therapy. Gen. Phirmac.,13: 333-341.

Mazhar, F.M. ; Ashry, M.A. and Kadry. S. A.(1986). Effects of environmental pollution on the hisiological features of the major organs of the Nile catfish; Clurias lazera. Proc. Zool. Soc. A. R. Egypt., 12: 75-89.

Mehrle, P. M. and Mayer, F. L. (1976). "Abstract of papers" 172 nd. National meeting of the American Chemical Society, Washington, D. C., Pest, 85.

Mirvish,S.S. (1975). Blocking the formation of N-nitroso compounds in vitro and in vivo. Ann. N. Y. Acad. Sci.,258:175-180.

Rady, M. I. (1997). The comparative biological changes induced by some ecological pollutants in certain fishes, Ph. D. Thesis, Faculty of Science, Al-Azhar University, Egypt,P. 298, 299 $\& 307$.

Sakr, S. A. and Al-Sahhaf, Z.Y.(1996). Histopathological alteration in the liver and testes of toad; Bufo tibamicus, intoxicated with the insecticide lannate. J.Egypt. Ger.Soc.Zool.,19 (C): 53-67.

Wester, P. W. (1988). Toxicological pathology in fish, Ph. D. Thesis, Rijks Universitet te utrecht, The Netherland, P. 208.

Yamamoto,Y.; Hayama, K. and Ikeda, S.(1981). Effect of dietary ascorbic acid on the copper poisoning in rainbow trout, Bull. Japan. Soc. Sci. Fish.,47: 1085. 


\section{Plate "A"}

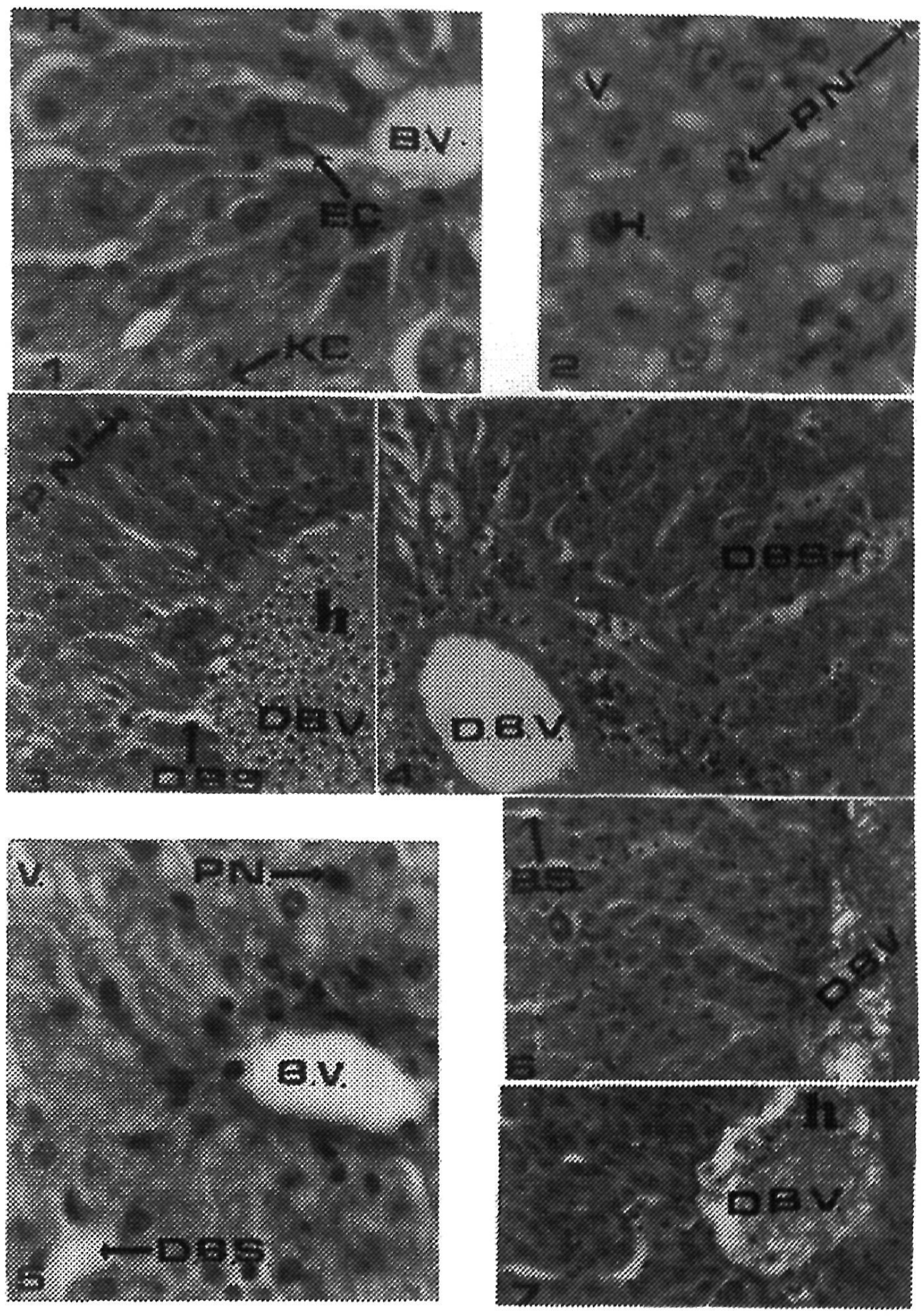




\section{Plate "B"}
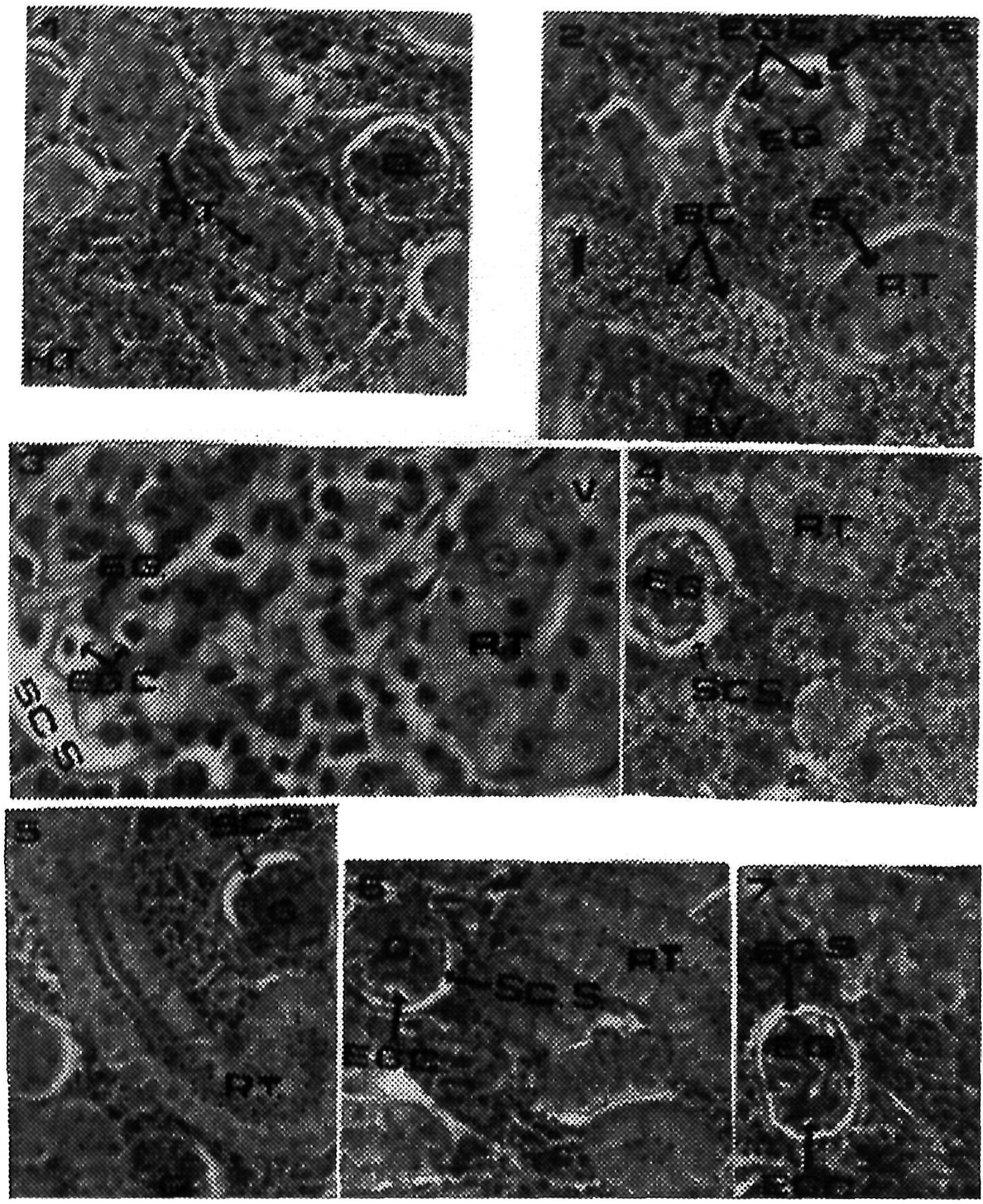